Manuela Nickler ${ }^{a}$, Daniela Schaffner ${ }^{a}$, Mirjam Christ-Crain, Manuel Ottiger, Robert Thomann, Claus Hoess, Christoph Henzen, Beat Mueller and Philipp Schuetz*, for the proHOSP Study Group

\title{
Prospective evaluation of biomarkers for prediction of quality of life in community-acquired pneumonia
}

DOI 10.1515/cclm-2016-0001

Received January 1, 2016; accepted March 10, 2016; previously published online April 21, 2016

\section{Abstract}

Background: Most clinical research investigated prognostic biomarkers for their ability to predict cardiovascular events or mortality. It is unknown whether biomarkers allow prediction of quality of life (QoL) after survival of the acute event. Herein, we investigated the prognostic potential of well-established inflammatory/cardiovascular blood biomarkers including white blood cells (WBC), C-reactive protein (CRP), procalcitonin (PCT), pro-adrenomedullin (proADM) and pro-atrial natriuretic peptide (proANP) in regard to a decline in QoL in a well-defined cohort of patients with community-acquired pneumonia (CAP).

Methods: Within this secondary analysis including 753 patients with a final inpatient diagnosis of CAP from a

${ }^{a}$ Manuela Nickler and Daniela Schaffner contributed equally to this work.

*Corresponding author: Prof Dr. med. Philipp Schuetz, MD, MPH, Division of General Internal and Emergency Medicine, University Department of Medicine, Kantonsspital Aarau, Tellstrasse, 5001 Aarau, Switzerland, Phone: +41 (0)62 838 4141, Fax: +41 (0)62 838 4100, E-mail: schuetzph@gmail.com; and Department of Emergency Medicine, Beth Israel Deaconess Medical Center, Harvard School of Public Health, Boston, MA, USA Manuela Nickler, Daniela Schaffner, Manuel Ottiger and Beat Mueller: Division of General Internal and Emergency Medicine, Medical University Department, Kantonsspital Aarau, Aarau, Switzerland

Mirjam Christ-Crain: Department of Internal Medicine, Division of Endocrinology, Diabetes and Clinical Nutrition, University Hospital Basel, Basel, Switzerland

Robert Thomann: Department of Internal Medicine, Bürgerspital Solothurn, Solothurn, Switzerland

Claus Hoess: Department of Internal Medicine, Kantonsspital Münsterlingen, Switzerland

Christoph Henzen: Department of Internal Medicine, Kantonsspital Lucerne, Lucerne, Switzerland multicenter trial, we investigated associations between admission biomarker levels and decline in QoL assessed by the EQ-5D health questionnaire from admission to day 30 and after 6 years.

Results: Admission proADM and proANP levels significantly predicted decline of the weighted EQ-5D index after 30 days $(\mathrm{n}=753)$ with adjusted odds ratios (ORs) of 2.0 ([95\% CI 1.1-3.8]; $\mathrm{p}=0.027$ ) and 3.7 ([95\% CI 2.2-6.0]; $\mathrm{p}<0.001)$. Results for 6-year outcomes $(n=349)$ were similar with ORs of 3.3 ([95\% CI 1.3-8.3]; $\mathrm{p}=0.012$ ) and 6.2 ([95\% CI 2.7-14.2]; $\mathrm{p}<0.001)$. The markers were associated with most of the different QoL dimensions including mobility, self-care, and usual activities, but not pain/ discomfort and to a lesser degree anxiety/depression and the visual analogue scale (VAS). Initial WBC, PCT and CRP values did not well predict QoL at any time point.

Conclusions: ProADM and proANP accurately predict short- and long-term decline in QoL across most dimensions in CAP patients. It will be interesting to reveal underlying physiopathology in future studies.

Keywords: anxiety; community-acquired pneumonia; C-reactive protein; depression; discomfort; EQ-5D index; mobility; pain; pro-adrenomedullin; pro-atrial natriuretic peptide; procalcitonin; quality of life; self-care; usual activities; VAS; white blood cells.

\section{Introduction}

Community-acquired pneumonia (CAP) is the leading cause of death from infectious disease [1], and is responsible for high mortality, morbidity, and costs worldwide $[2,3]$. Pneumonia is not only associated with high shortterm mortality $[4,5]$, but even more substantial longterm mortality rates in patients surviving an initial CAP episode, as compared to the general population and to patients suffering from other infections, respectively [611]. In addition, CAP is associated with a higher short- and 
long-term risk of adverse cardiovascular events compared to controls [12], and pneumonia has lately been proposed to be an independent cardiovascular risk factor [12]. Importantly, quality of life (QoL) in individuals surviving a CAP episode has become an important health care indicator and should also be considered when looking at CAP outcomes.

Much research has focused on short- and long-term outcome prognostication in the CAP patient population. This may help to better guide initial site-of-care decisions, and optimize discharge strategies and post-discharge outpatient management. In addition to clinical risk scores, such as the pneumonia severity index (PSI) [13], several inflammatory and/or cardiovascular blood biomarkers such as white blood cells (WBC), C-reactive protein (CRP), procalcitonin (PCT), pro-adrenomedullin (proADM), as well as pro-atrial natriuretic peptide (proANP) have been found helpful for risk prediction [6, 14-20]. Particularly, proADM [9, 6, 21-30], proANP [9, 6, 25, 31-33] and PCT [10, $22,25,31,34-36]$ have been associated with risk for shortand long-term all-cause mortality as well as other adverse outcomes, such as severity of illness, admission to the intensive care unit (ICU), and disease-specific complications. Yet, there is insufficient evidence whether these clinical parameters and blood biomarkers are also helpful in predicting more subjective QoL outcomes: mens sana in corpore sano?

Herein, our aim was to study prognostic biomarkers for their ability to predict a decline in QoL in a welldefined cohort of CAP patients. The early and accurate identification of patients being at risk for a decline in QoL after an index hospitalization for CAP may optimize patient satisfaction, inhospital and discharge management, and improve our pathophysiological understanding of this disease.

\section{Materials and methods}

\section{Aims}

The prognostic accuracy of previously published inflammatory and cardiovascular blood biomarkers was investigated to predict a decline in QoL in the short-term (30 days) and long-term (6 years).

\section{Study design and setting}

This is a secondary analysis from a prospective randomized-controlled, multi-center trial performed at six Swiss secondary or tertiary care centers between October 2006 and March 2008 [37]. A detailed study protocol of the initial trial has been published elsewhere [38]. Briefly, from a total of 1825 potential patients admitted to the emergency department (ED), 925 subjects with a final inpatient diagnosis of CAP were included on admission. The aim of the initial prospective, multicenter, randomized-controlled trial was to assess the efficacy and safety of PCT guided antibiotic therapy compared to standard guidelines without using PCT data [39-41] in hospitalized patients with lower respiratory tract infections [37].

The study protocol was approved by the Ethics Committee of the University of Basel as well as by all Local Ethics Committees, written informed consent was provided by all participants for the initial trial, including agreement to use their data anonymized in secondary analyses.

\section{Selection and assessment of participants}

Inclusion criteria were age $>18$ years and final diagnosis of CAP with an infiltrate on chest X-ray [37, 40, 42]. Exclusion cirteria were language restriction or dementia precluding patients from providing written informed consent, a terminal condition, intravenous drug abuse as well as hospital-acquired pneumonia. Additionally, patients were excluded due to severe immunosuppression or longterm antibiotic therapy on admission, while being a recipient of corticosteroids or short-term antibiotic pretreatment were allowed.

Patient assessment included clinical and biochemical evaluation upon admission to the ED and throughout the period of hospitalization. The standardized baseline characteristics comprised medical history, comorbidities (identified either through patient selfreport or medical chart review), vital signs, laboratory values, chest $\mathrm{X}$-ray and medication. To assess disease severity, the PSI [13] and the confusion, urea, respiratory rate, blood pressure, age $>65$ years (Curb-65 score) [40] - validated risk assessment tools to categorize CAP patients into different risk classes - were calculated upon ED admission. Discharge decision concerning patients enrolled in the study was completely left to the treating physicians without interference of the study team.

For the present analysis, all of initially included 925 patients with a final inpatient diagnosis of CAP were eligible for analysis, if they had available information on admission blood biomarker levels and if they survived until the follow-up period for completion of the QoL assessment performed at 30 days and 6 years. After exclusion of 50 non-survivors (5\%) at day 30 and 417 non-survivors (45\%) at 6 years, as well as $122(13 \%)$ and 159 (17\%) survivors with missing information on the QoL assessment, the final cohort consists of 753 of 925 patients (81\%) for the day 30 analysis, and 349 of 925 patients (38\%) for the 6-year analysis.

\section{Analysis of blood biomarkers}

Within the initial trial, blood samples for later measurement of different biomarkers were collected upon admission to the ED and throughout the hospitalization period. In the present analysis, we focused on five inflammatory and/or cardiovascular markers (WBC, CRP, PCT, proADM and proANP). Determination of WBC, CRP and PCT was done during clinical routine, while proADM and proANP were determined by batch analysis only after study completion. For quantification of PCT levels, an automated, sensitive assay (KRYPTOR PCT; Thermo Scientific Biomarkers [formerly BRAHMS AG], 


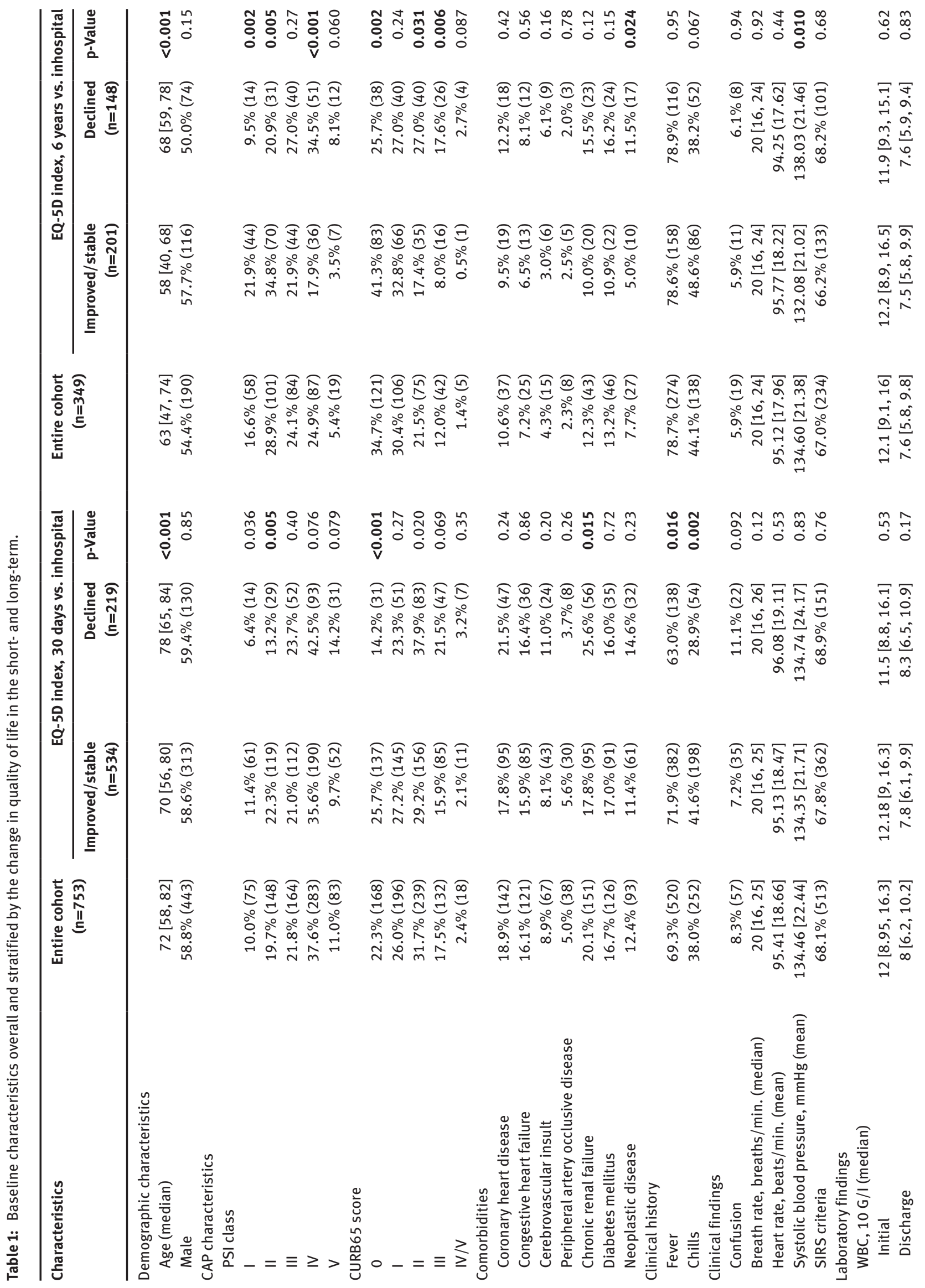




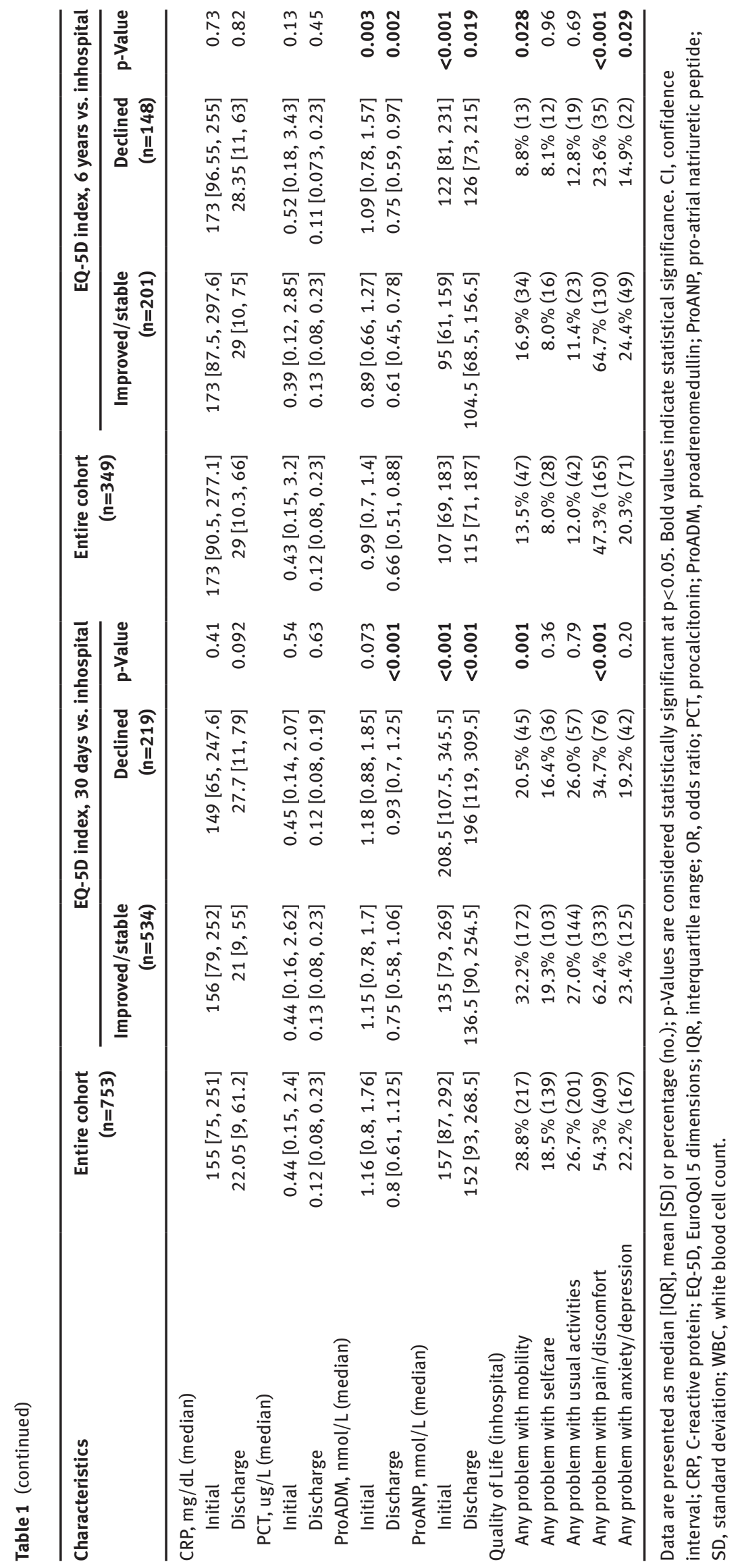


Table 2: Initial blood biomarker levels alone or combined with a clinical model to predict a decline in quality of life, measured by the weighted EQ-5D index, in CAP: univariate/multivariate logistic regression analyses and ROC curve analyses of accuracy.

\begin{tabular}{|c|c|c|c|c|}
\hline & \multicolumn{4}{|l|}{ Decline in EQ-5D index } \\
\hline & \multicolumn{2}{|c|}{30 days vs. inhospital $(n=753)$} & \multicolumn{2}{|c|}{6 years vs. inhospital $(n=349)$} \\
\hline \multicolumn{5}{|c|}{ Univariate and multivariate analyses } \\
\hline Univariate model & $1.09(0.50-2.37)$ & $p=0.829$ & $1.03(0.34-3.09)$ & $p=0.960$ \\
\hline Combined model ${ }^{\mathrm{a}}$ & $1.24(0.55-2.80)$ & $\mathrm{p}=0.598$ & $1.16(0.33-4.02)$ & $\mathrm{p}=0.815$ \\
\hline \multicolumn{5}{|l|}{ Prognostic accuracy } \\
\hline Univariate model & $0.49(0.44-0.53)$ & & $0.48(0.42-0.54)$ & \\
\hline \multicolumn{5}{|l|}{ CRP } \\
\hline \multicolumn{5}{|c|}{ Univariate and multivariate analyses } \\
\hline Univariate model & $0.88(0.63-1.24)$ & $\mathrm{p}=0.470$ & $1.05(0.66-1.65)$ & $\mathrm{p}=0.845$ \\
\hline Combined model ${ }^{\mathrm{a}}$ & $0.86(0.60-1.22)$ & $\mathrm{p}=0.388$ & $1.04(0.63-1.71)$ & $\mathrm{p}=0.889$ \\
\hline \multicolumn{5}{|l|}{ Prognostic accuracy } \\
\hline Univariate model & $0.48(0.43-0.53)$ & & $0.49(0.43-0.55)$ & \\
\hline \multicolumn{5}{|l|}{ РСТ } \\
\hline \multicolumn{5}{|c|}{ Univariate and multivariate analyses } \\
\hline Univariate model & $0.96(0.78-1.18)$ & $p=0.716$ & $1.20(0.92-1.57)$ & $p=0.171$ \\
\hline Combined model ${ }^{\mathrm{a}}$ & $0.97(0.79-1.20)$ & $\mathrm{p}=0.809$ & $1.22(0.91-1.64)$ & $\mathrm{p}=0.186$ \\
\hline \multicolumn{5}{|l|}{ Prognostic accuracy } \\
\hline Univariate model & $0.49(0.44-0.53)$ & & $0.55(0.49-0.61)$ & \\
\hline \multicolumn{5}{|c|}{ ProADM } \\
\hline \multicolumn{5}{|c|}{ Univariate and multivariate analyses } \\
\hline Univariate model & $1.64(0.91-2.94)$ & $p=0.100$ & $2.76(1.23-6.20)$ & $p=0.014$ \\
\hline Combined model ${ }^{\mathrm{a}}$ & $2.03(1.08-3.80)$ & $\mathrm{p}=0.027$ & $3.28(1.30-8.29)$ & $p=0.012$ \\
\hline \multicolumn{5}{|l|}{ Prognostic accuracy } \\
\hline Univariate model & $0.54(0.50-0.58)$ & & $0.59(0.53-0.65)$ & \\
\hline \multicolumn{5}{|l|}{ ProANP } \\
\hline \multicolumn{5}{|c|}{ Univariate and multivariate analyses } \\
\hline Univariate model & $2.58(1.64-4.04)$ & $\mathrm{p}<0.001$ & $3.50(1.75-7.01)$ & $\mathrm{p}<0.001$ \\
\hline Combined model ${ }^{\mathrm{a}}$ & $3.66(2.22-6.03)$ & $\mathrm{p}<0.001$ & $6.16(2.68-14.20)$ & $\mathrm{p}<0.001$ \\
\hline \multicolumn{5}{|l|}{ Prognostic accuracy } \\
\hline Univariate model & $0.60(0.56-0.65)$ & & $0.62(0.56-0.67)$ & \\
\hline
\end{tabular}

Data for univariate and multivariate analyses are presented as OR $(95 \% \mathrm{Cl})$, p-Value; $\mathrm{p}$-Values are considered statistically significant at $\mathrm{p}<0.05$. Data regarding prognostic accuracy are presented as AUC $(95 \% \mathrm{CI})$; an AUC of 0.5 indicates coin-toss accuracy, while 1.0 indicates $100 \%$ accuracy. Bold values indicate statistical significance and prognostic accuracy better than coin-toss, respectively. AUC, area under the receiver operating characteristic curve; $\mathrm{Cl}$, confidence interval; $\mathrm{CRP}, \mathrm{C}$-reactive protein; EQ-5D, EuroQol 5 dimensions; OR, odds ratio; PCT, procalcitonin; ProADM, proadrenomedullin; ProANP, pro-atrial natriuretic peptide; ROC, receiver operating characteristic (curve); WBC, white blood cell count. ${ }^{a}$ Combined model is adjusted for baseline values of each dimension of the EQ-5D descriptive system comprising mobility, self-care, usual activities, pain/discomfort, anxiety/depression.

Henningsdorf, Germany) was used, showing a lower detection limit of $0.02 \mu \mathrm{g} / \mathrm{L}$ and a functional sensitivity of $0.06 \mu \mathrm{g} / \mathrm{L}$. Measurements of proADM plasma levels were performed by a sandwich immunoassay with a lower detection limit of $0.08 \mathrm{nmol} / \mathrm{L}$ [43, 44]. Determination of proANP plasma levels was performed by another sandwich immunoassay (BRAHMS AG, Henningsdorf/Berlin, Germany) with a lower detection limit of $4.3 \mathrm{pmol} / \mathrm{L}$ and a functional sensitivity of $11 \mathrm{pmol} / \mathrm{L}$, as previously described [45].

\section{Patient outcomes}

The primary endpoint of this study was a decline in QoL from hospital admission (baseline) to day 30 and after 6 years. For this purpose,
QoL was measured with the EQ-5D health questionnaire as recommended [46-48] in the ED on the day of admission - assessing QoL of the past 7 days - and by telephone interviews during the follow-up. The EQ-5D comprises the five-item tool EQ- $5 \mathrm{D}_{\text {self-classifier }}$, a descriptive system, which assesses the health-related QoL along the following five dimensions: 'mobility', 'self-care', 'usual activities', 'pain/ discomfort' and 'anxiety/depression'. Each domain is expressed by three severity levels. Importantly, the EQ-5D instrument provides calculation of a weighted country-specific single index value [49], considered as primary endpoint. It additionally includes the EQ VAS recording the patients' self-rated health state on a vertical scale as a quantitative measurement.

Secondary endpoints were defined as a decline in the different 5 dimensions of EQ-5D and in the self-reported health state using the EQ VAS after 30 days and 6 years post-discharge. 


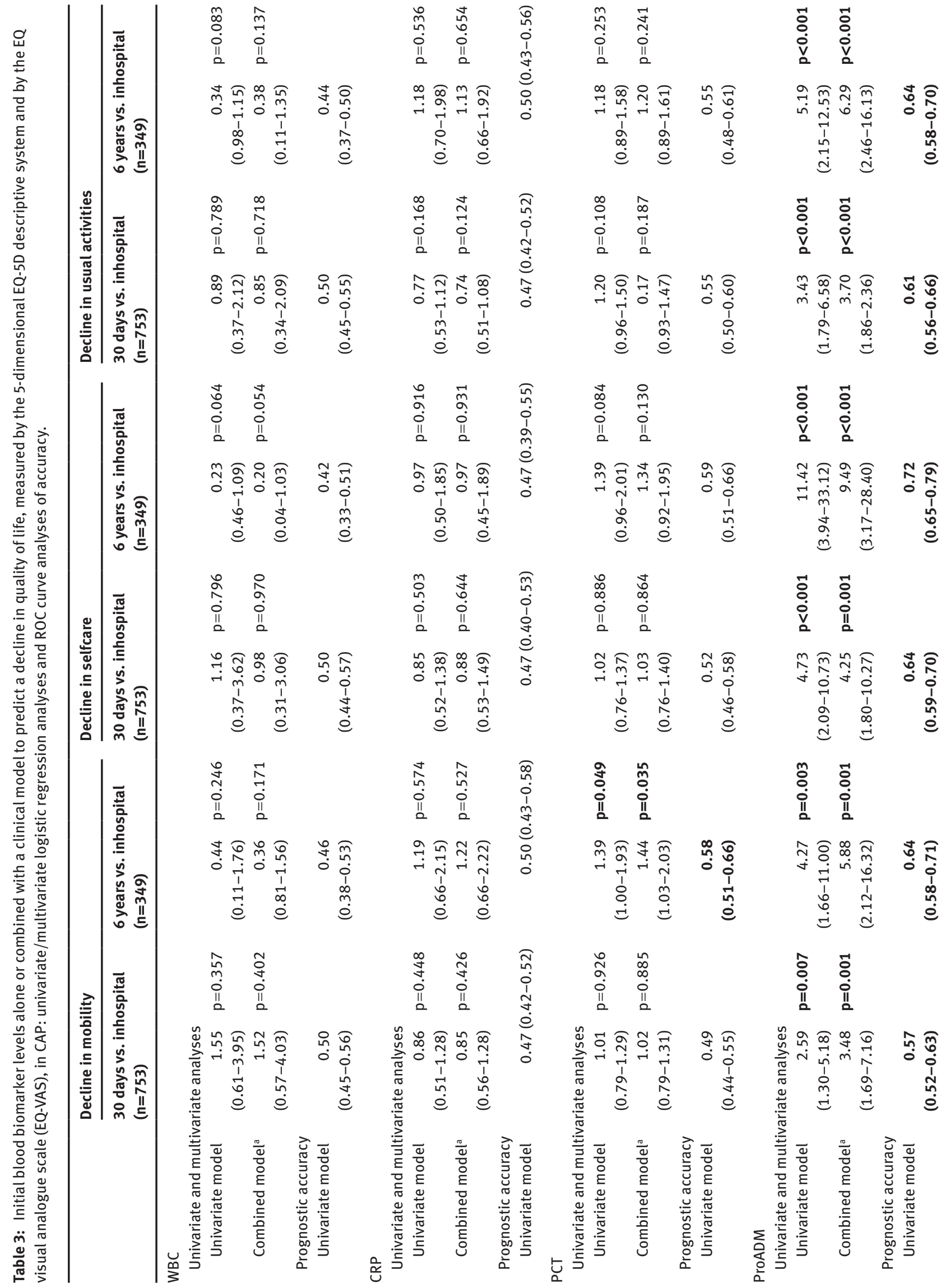




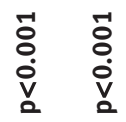

ำ $\bar{m} \%$

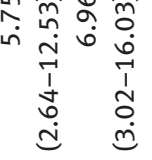

$\begin{array}{ll}\vec{b} & \vec{o} \\ \dot{0} & \dot{v} \\ \text { v } & \text { v }\end{array}$

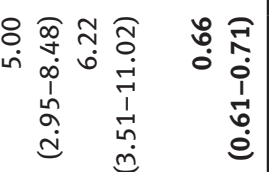

\begin{tabular}{ll}
$\vec{o}$ & $\vec{b}$ \\
$\dot{0}$ & $\dot{v}$ \\
v & \multicolumn{1}{c}{}
\end{tabular}

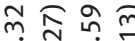

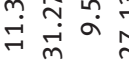

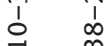

过

กั

$\begin{array}{ll}\vec{o} & \overrightarrow{0} \\ \dot{0} & \dot{v} \\ \text { v } & \text { v }\end{array}$

해웡ㅇㅇ

เก

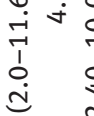

\section{$\begin{array}{ll}\overrightarrow{0} & \overrightarrow{0} \\ \dot{0} & \dot{0} \\ 0 & 0\end{array}$}

mo 0

ن. $\begin{array}{ll}1 & 1 \\ 6 & 0\end{array}$

¿.

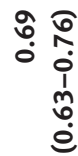

\section{$\overline{8} \overline{8}$ \\ v v}

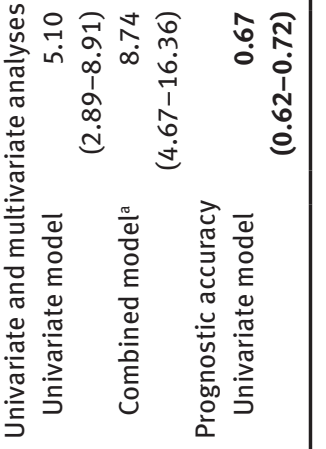

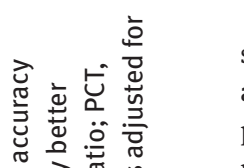

\section{Results}

\section{Baseline characteristics}

Baseline characteristics of the entire cohort and stratified by the primary endpoint, i.e. the change in QoL at 30 days and 6 years, are presented in Table 1 . The study included 753 patients for the analysis after 30 days and 349 after 6 years. A total of $29 \%$ of patients showed a decline in QoL at 30 days and $42 \%$ after 6 years. Median age of the entire cohort was 72 years, and patients had a high burden of comorbidities with 19\% (142) of patients suffering from coronary heart disease, 16\% (121) congestive heart failure, $20 \%$ (151) chronic renal failure, 17\% (126) diabetes mellitus and 12\% (93) neoplastic disease.

Patients with a decline in QoL had higher age as compared to individuals with no decline at both time points. There was no difference in terms of gender and comorbidities except for chronic renal failure (26\% vs. $18 \%$ ) and neoplastic disease (12\% vs. $5 \%$ ). In regard to biomarkers, discharge values of proADM and both admission and discharge levels of proANP were increased in patients with a 


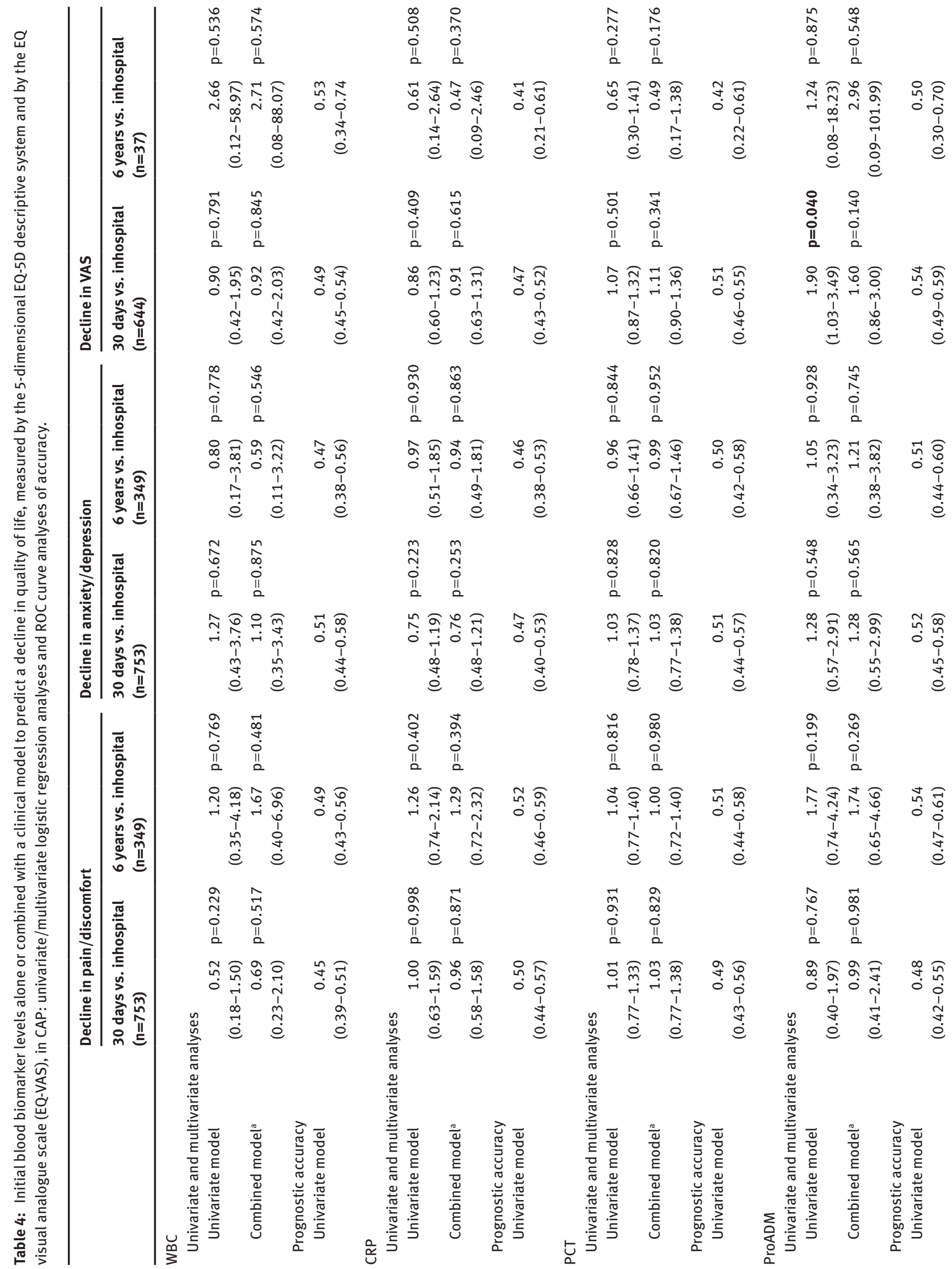




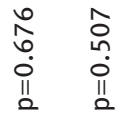

ํำว

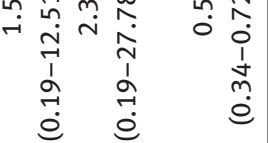

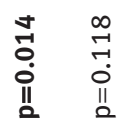

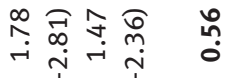

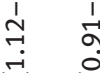

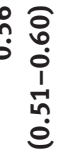

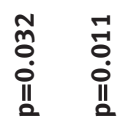

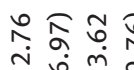

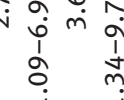

$\overrightarrow{0}$

㲾

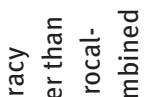

decline in QoL. In contrast, there were no differences in levels of WBC, CRP and PCT.

\section{Associations between blood biomarker levels and quality of life}

Table 2 shows the results of uni- and multivariate logistic regression analyses assessing associations of initial blood biomarker values and a decline in QoL after 30 days and 6 years. In the adjusted model including adjustment for baseline QoL, significant associations of initial proADM and proANP levels with a decline in the weighted EQ-5D index after a 30-day follow-up period was found with ORs of 2.0 ([95\% CI 1.1-3.8]; $\mathrm{p}=0.027$ ) and 3.7 ([95\% CI 2.2-6.0]; $\mathrm{p}<0.001)$. For a decline over 6 years, results were similar with ORs of 3.3 ([95\% CI 1.3-8.3]; $\mathrm{p}=0.012)$ and 6.2 ([95\% CI 2.7-14.2]; $\mathrm{p}<0.001$ ) for proADM and proANP. As presented in Table 2, no associations were found for initial values of $\mathrm{WBC}$, CRP, PCT.

In a secondary analysis, we also focused on a decline in the different QoL dimensions as well as a decline in VAS (Tables 3 and 4). Regression analyses demonstrated, that proADM and proANP levels were significantly associated with worsening in 'mobility', 'self-care' and 'usual activities' over both 30 days and 6 years. This association remained robust after adjustment for baseline QoL (Table 3). As presented in Table 4, only proANP was associated with a decline in the 'anxiety/depression' dimension, while proADM was not. In addition, no associations with measured biomarker levels were found for a decline in 'pain/discomfort' and the VAS after model adjustment.

We also calculated area under the receiver operating curve (AUC) of the different markers and decline of QoL (Tables 2-4), as well as prognostic accuracy measures including sensitivities, specificities, negative and positive predictive values. For proADM, these measures showed at an optimal cut-off of $1.33 \mathrm{nmol} / \mathrm{L}$ a sensitivity of $44 \%$ and specificity of $62 \%$ with positive and negative predictive values of $33 \%$ and $73 \%$, respectively. At the optimal cut-off of $168 \mathrm{nmol} / \mathrm{L}$ of proANP, the sensitivity was $61 \%$ with a specificity of $59 \%$ and positive and negative predictive values of $39 \%$ and $78 \%$.

To further illustrate these findings, results of adjusted logistic regression models are presented in forest plots (Figures 1-4), demonstrating blood biomarker values according to the change in QoL.

We also investigated discharge as well as high peak levels of the respective blood biomarkers, and their association with QoL, showing similar results (data not shown). 


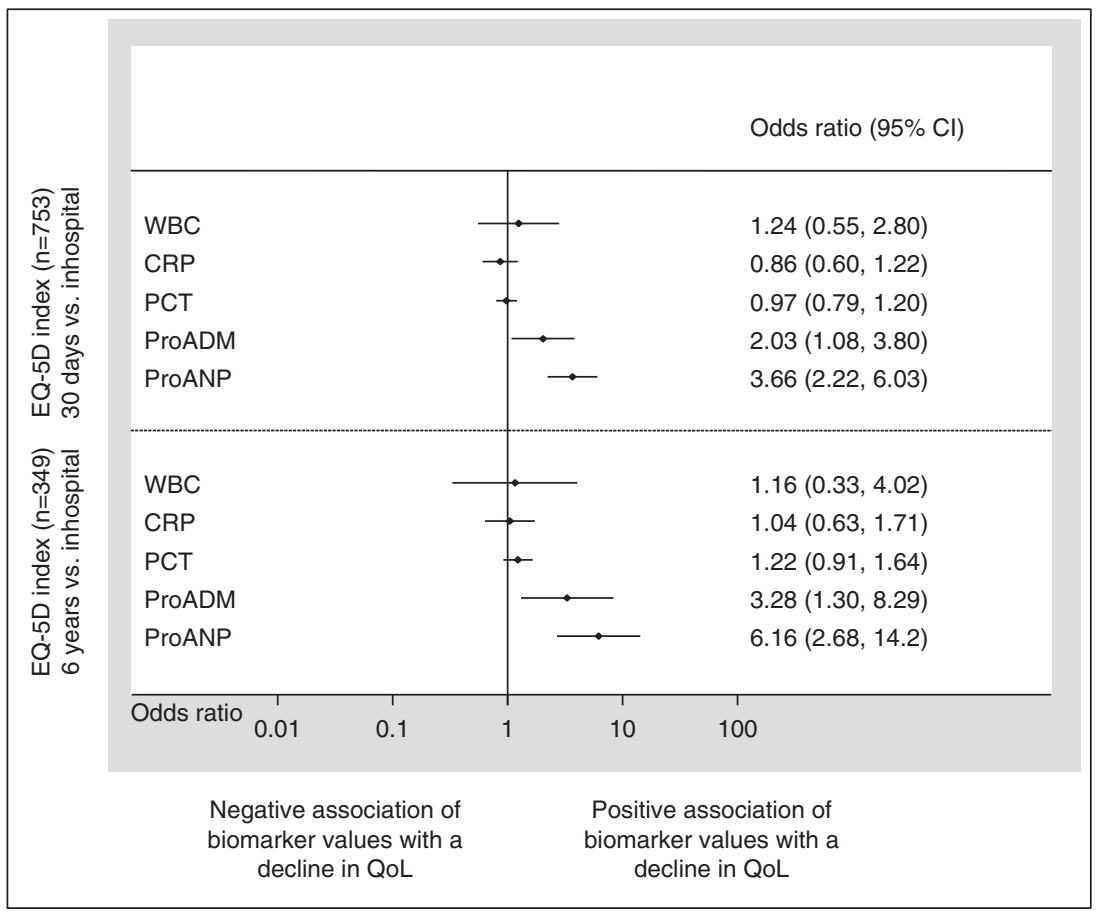

Figure 1: Forest plot showing odds ratios of blood biomarker values according to the change in QoL, measured by the EQ-5D index, over a 30-day and 6-year follow-up period.

Odds ratios $>1$ reflect a positive association between biomarker levels and worsening of QoL. Models are adjusted for baseline values of each dimension of the EQ-5D descriptive system comprising mobility, self-care, usual activities, pain/discomfort, anxiety/depression. CAP, community-acquired pneumonia; $\mathrm{Cl}$, confidence interval; CRP, C-reactive protein; EQ-5D, EuroQol 5 dimensions; OR, odds ratio; PCT, procalcitonin; ProADM, proadrenomedullin; ProANP, pro-atrial natriuretic peptide; QoL, quality of life; WBC, white blood cell count.

\section{Discussion}

The findings of this first study investigating the ability of circulating inflammatory and cardiovascular biomarker levels to predict a decline in QoL in CAP patients are two-fold. First, proADM and proANP predicted worsening in the weighted QoL index over 30 days and 6 years in patients hospitalized for CAP. Other prognostic inflammatory markers including WBC, CRP and PCT did not show any significant association. Second, regarding the different dimensions of QoL as assessed with the EQ-5D descriptive system, changes in 'mobility', 'self-care' and 'usual activities' were strongly associated with high levels of proADM and proANP in the short- and long-term, whereas impairment in the domain 'pain/discomfort' and the VAS showed no association after model adjustment.

Multiple studies have demonstrated that suffering from CAP is an indicator of poor prognosis with impaired short- and long-term outcome [4-11]. CAP per se is associated with an increased rate of adverse cardiovascular events [12]. On the one hand comorbidities such as cardiac disease and malignancy might be the reasons for this poor prognosis, on the other hand, pneumonia itself has recently been proposed to be an independent cardiovascular risk predictor [12]. Thereby inflammatory host response might act as a relevant contributor by modifying the ratio between prothrombotic and antithrombotic factors. Due to this hard endpoints, it is crucial to pay attention to patients' subjective QoL in time following a CAP episode. Early identification of those being at risk for a decline in QoL could lead to improved health state by providing individual medical resources such as physical therapy, prescription of a walking stick/frame, registration at a retirement or nursing home as well as, e.g. psychological support even at an early stage of disease. This in turn might result in a reduction of rehospitalization rates and outpatient visits, potentially lowering health care costs. The present analysis of a large, well-characterized cohort provides novel insights into the prediction of patient-specific QoL outcomes in hospitalized CAP and is thus worth mentioning.

Based on several clinical observational studies, circulating proADM and proANP have lately emerged as useful prognostic tools regarding all-cause mortality, ICU 


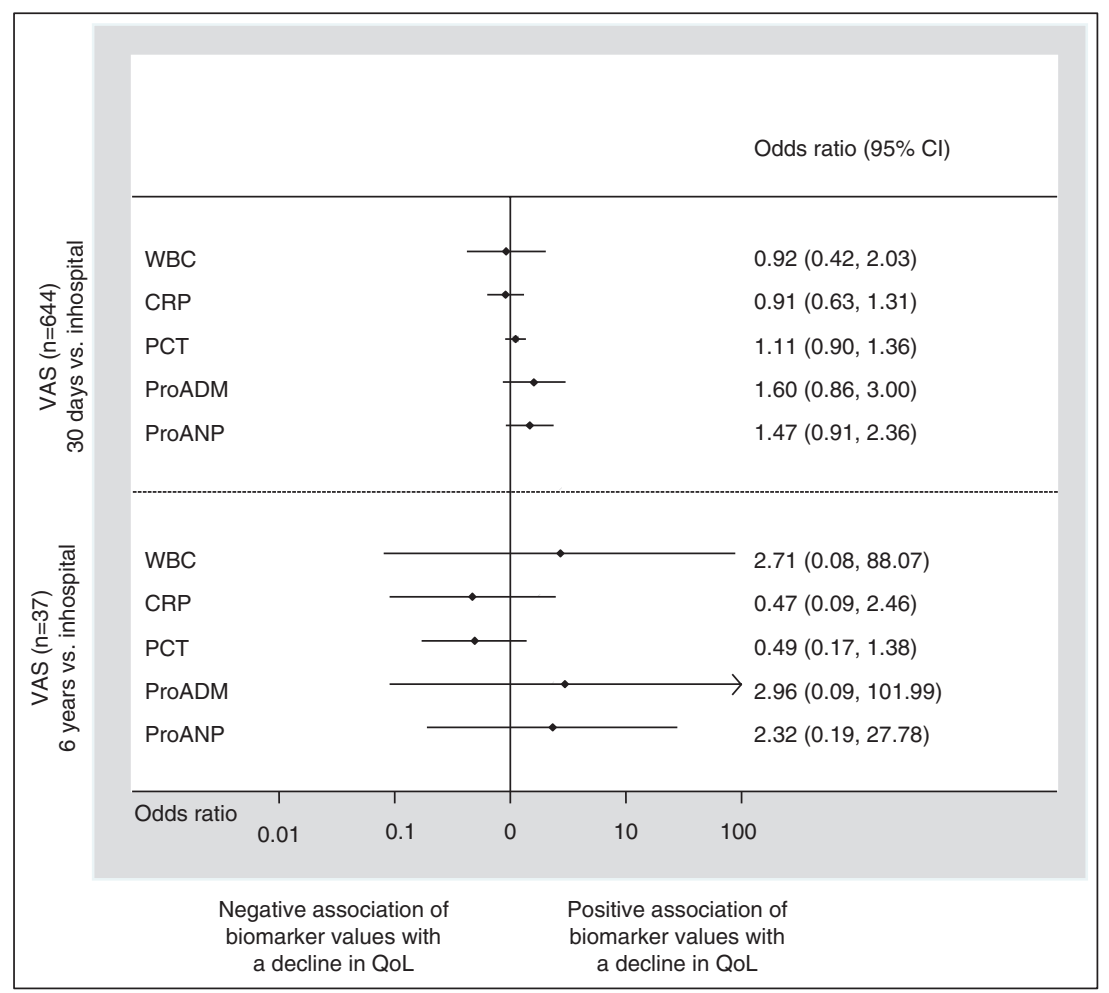

Figure 2: Forest plot showing odds ratios of blood biomarker values according to the change in QoL, measured by the EQ-VAS, over a 30-day and 6-year follow-up period.

Odds ratios >1 reflect a positive association between biomarker levels and worsening of QoL. Models are adjusted for baseline values of each dimension of the EQ-5D descriptive system comprising mobility, self-care, usual activities, pain/discomfort, anxiety/depression. CAP, community-acquired pneumonia; $\mathrm{Cl}$, confidence interval; CRP, C-reactive protein; EQ-5D, EuroQol 5 dimensions; OR, odds ratio; PCT, procalcitonin; ProADM, proadrenomedullin; ProANP, pro-atrial natriuretic peptide; QoL, quality of life; VAS, visual analogue scale; WBC, white blood cell count.

admission, severity of illness and disease-specific complications in CAP [9, 6, 25, 31-33]. The present analysis expands these findings by demonstrating a relevant correlation between high proADM and proANP levels and future decline in QoL in CAP patients. Since proADM acts as an immune regulatory peptide [50-54] as well as a potent vasodilatator $[55,56]$, and is upregulated due to hypoxia, inflammatory conditions, bacterial products and shear stress [51, 52, 57-60], it is tempting to speculate that the grade of respiratory insufficiency and the acute inflammatory host response during a CAP episode might have a relevant impact on patients' QoL in the short- and long-term. Moreover, considering proADM as a cardiovascular peptide $[55,56]$, high circulating levels might indicate a chronic condition of vascular stress based on endothelial damage, again potentially resulting in future health state impairment. ANP, a member of the family of natriuretic peptides, regulates natriuresis and diuresis, and lowers systemic blood pressure [61, 62]; additionally, increased proANP concentrations have been observed in patients suffering from severe infections [63]. Thus, proADM and proANP may mirror both, the acute inflammatory response reflecting the actual state of disease, and the concomitance of cardiovascular comorbidities as a static component. It must be emphasized that results of logistic regression analyses according to the change in the EQ-5D index were similar for admission and discharge proADM and proANP levels, assuming discharge values to basically represent the chronic state of expression.

Considering the lower predictive ability of proADM and proANP according to 'pain/discomfort' and 'anxiety/ depression' compared to the other documented QoL domains, one could hypothesize that the former two dimensions underly other pathophysiological mechanisms than the categories 'mobility', 'selfcare' and 'usual activities'. It is likely, that discomfort and feelings of being depressed or anxious are rather influenced by psychological and social factors, than by the state of inflammation or concomitant cardiovascular disease. This assumption needs verification in future studies. On the other hand, it 


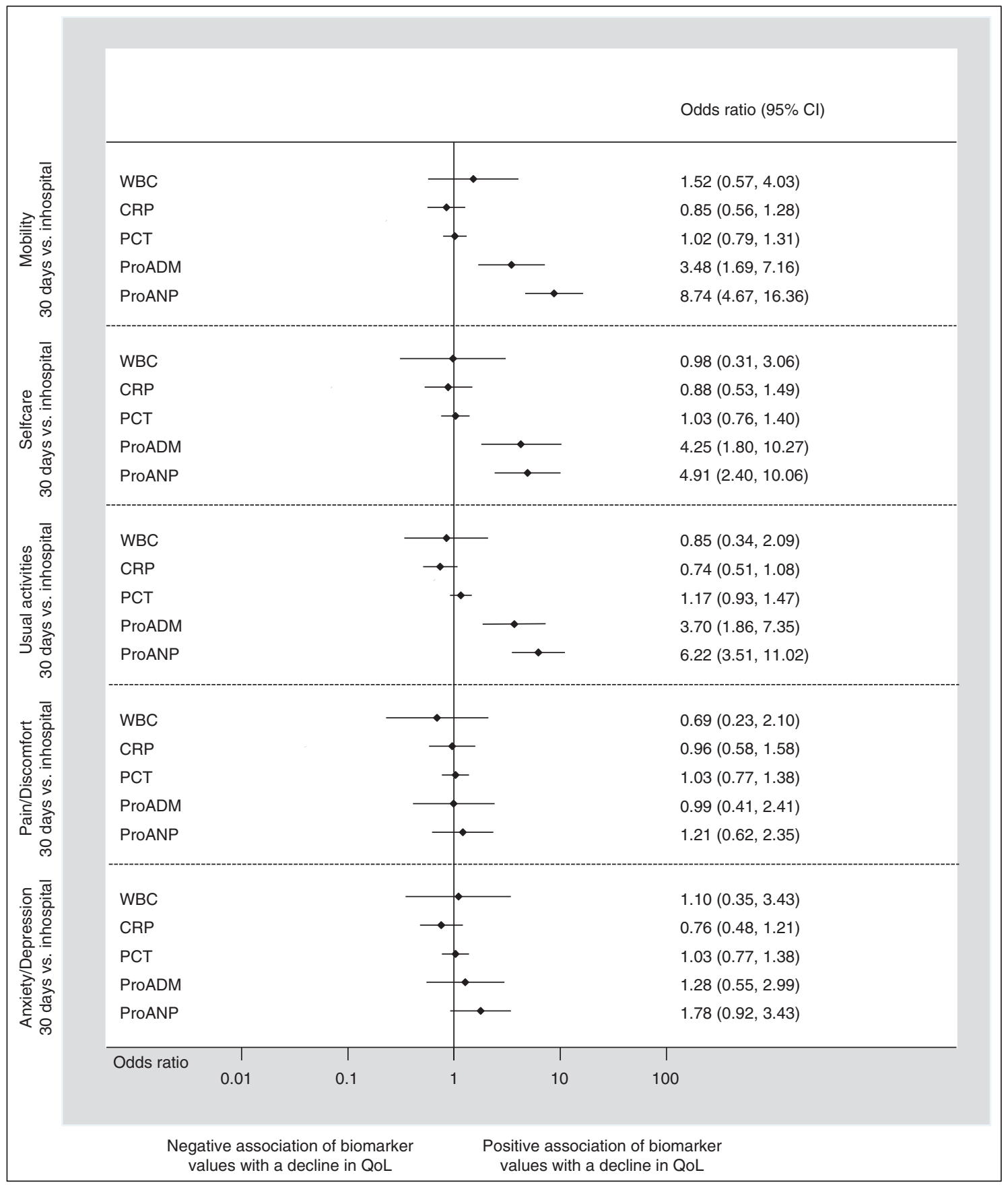

Figure 3: Forest plot showing odds ratios of blood biomarker values according to the change in QoL, measured by the EQ-5D descriptive system, over a 30-day follow-up period $(n=753)$.

Odds ratios $>1$ reflect a positive association between biomarker levels and worsening of QoL. Models are adjusted for baseline values of each dimension of the EQ-5D descriptive system comprising mobility, self-care, usual activities, pain/discomfort, anxiety/depression. CAP, community-acquired pneumonia; $\mathrm{Cl}$, confidence interval; CRP, C-reactive protein; EQ-5D, EuroQol 5 dimensions; OR, odds ratio; PCT, procalcitonin; ProADM, proadrenomedullin; ProANP, pro-atrial natriuretic peptide; QoL, quality of life; WBC, white blood cell count.

should be taken into account, that pain and discomfort as well as anxiety and depression might exhibit a bigger variety during the day because of diurnal mood fluctuation, making it difficult to collect data homogenously. Otherwise, we assume patients' self-assessment in terms of current 'mobility', 'selfcare and 'usual activities' to be more stable in the daytime and thus easier to quantify. Importantly, in adjusted regression models none of the analyzed blood biomarkers correlated with self-reported health-state by VAS in the months and years after a CAP 


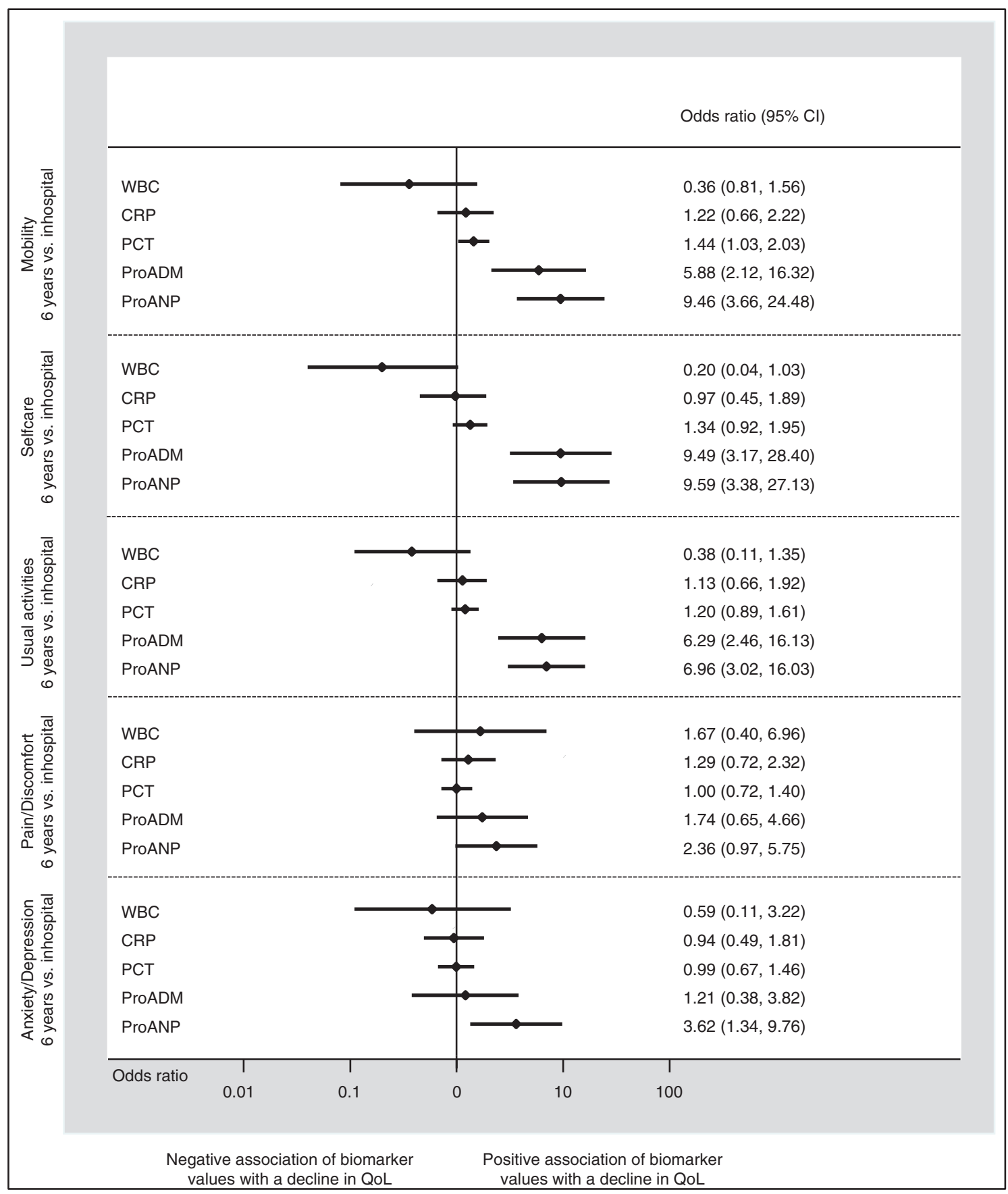

Figure 4: Forest plot showing odds ratios of blood biomarker values according to the change in QoL, measured by the EQ-5D descriptive system, over a 6-year follow-up period $(n=349)$.

Odds ratios $>1$ reflect a positive association between biomarker levels and worsening of QoL. Models are adjusted for baseline values of each dimension of the EQ-5D descriptive system comprising mobility, self-care, usual activities, pain/discomfort, anxiety/depression. CAP, community-acquired pneumonia; $\mathrm{Cl}$, confidence interval; CRP, C-reactive protein; EQ-5D, EuroQol 5 dimensions; OR, odds ratio; PCT, procalcitonin; ProADM, proadrenomedullin; ProANP, pro-atrial natriuretic peptide; QoL, quality of life; WBC, white blood cell count.

episode. Again, other potential predictors as well as the probable fluctuation intraday might have had an influence on the respective outcome.

The main strengths of this study include the welldefined and characterized cohort of patients hospitalized for CAP, the long follow-up period of 6 years and the thorough and highly accurate biomarker measurement methods. The large sample size and the high number of primary endpoints in the short- and long-term (29\% and $42 \%$, respectively) lead to high statistical power, which in 
turn allows detecting even small differences in biomarker levels. Nevertheless, the following limitations require consideration: First, the present study is a secondary analysis and therefore rather hypothesis generating. Second, the initial trial was conducted in different secondary and tertiary care hospitals in Switzerland, and thus results may not be applicable to other settings such as primary or intensive care, and other countries. Third, due to the exclusion of non-survivors, we assume the herein analyzed cohort to comprise healthier subjects as compared to the CAP population usually treated in EDs. This suggestion is in line with the observation that CAP non-survivors enrolled in the initial trial displayed a significantly higher concomitance of comorbidities and showed higher PSI values compared to survivors [6]. Thus, the present results might not unconditionally be generalizable to the severely ill. Due to the high number of non-survivors we did not do an analysis with imputation of the worst QoL value namely death - for these patients as the analysis would have been strongly driven by mortality. In addition, within our analysis we focused specifically on patients suffering from CAP; further studies are required to validate these findings for other medical and surgical patient populations. Also, our baseline QoL may has been affected by the acute medical situation in the ED and may differ thus from later measurements using telephone interviews. Finally, since this was an observational study, it is only hypothesis generating and correlation does not imply causality.

\section{Conclusions}

In conclusion, proADM and proANP levels allowed accurate short- and long-term prognostication regarding the change in QoL in hospitalized CAP. Importantly, proADM and proANP most accurately discriminate a decline in QoL as compared to WBC, CRP and PCT levels. An improved risk stratification in CAP regarding the change in QoL with an early risk-based, 'personalized' deployment of medical resources could potentially improve subsequent health state, reduce rehospitalization rates, decrease outpatient consultations, and may in turn contribute to a more costeffective patient management.

Acknowledgments: We are grateful to the emergency department, medical clinic, and central laboratory staff of the University Hospital Basel and the Cantonal Hospitals Aarau, Liestal, Lucerne, and Muensterlingen, and the 'Buergerspital' Solothurn for their assistance and technical support. In particular, we thank all patients, their relatives and all local general practitioners who participated in this study. Finally, we acknowledge the ProHOSP Study Group for their important support. The ProHOSP study group included the following persons: Ursula Schild, RN, Katharina Regez, RN, Rita Bossart, RN, Robert Thomann, MD, Claudine Falconnier, MD, Marcel Wolbers, PHD, Stefanie Neidert, MD, Thomas Fricker, MD, Claudine Blum, MD, Thomas Bregenzer, MD, Claus Hoess, MD, Heiner C. Bucher, MD, Fabian Mueller, Jeannine Haeuptle, Roya Zarbosky, Rico Fiumefreddo, MD, Melanie Wieland, RN, Charly Nusbaumer, MD, Andres Christ, MD, Roland Bingisser, MD, Kristian Schneider, RN, Brigitte Walz, PhD, Verena Briner, MD, Dieter Conen, MD, Andreas Huber, MD, Jody Staehelin, MD, Aarau, Chantal Bruehlhardt, RN, Ruth Luginbuehl, RN, Agnes Muehlemann, PhD, Ineke Lambinon, Werner Zimmerli, MD, and Max Zueger, MD.

Author contributions: All the authors have accepted responsibility for the entire content of this submitted manuscript and approved submission.

Research funding: The main sources of funding for the investigator-initiated ProHOSP study were the Swiss National Science Foundation (grant SNF 3200BO-116177/1), Santé Suisse and the Gottfried and Julia Bangerter-Rhyner Foundation.

Employment or leadership: MC-C, BM and PS have received grants from $\mathrm{B} \cdot \mathrm{R} \cdot \mathrm{A} \cdot \mathrm{H} \cdot \mathrm{M} \cdot \mathrm{S} /$ Thermo and bioMérieux; in addition, BM has served as a consultant to these companies. None of the other authors has any relevant industrial relationships.

Honorarium: None declared.

Competing interests: The funding organization(s) played no role in the study design; in the collection, analysis, and interpretation of data; in the writing of the report; or in the decision to submit the report for publication.

\section{References}

1. Kung HC, Hoyert DL, Xu J, Murphy SL. Deaths: final data for 2005. Natl Vital Stat Rep 2008;56:1-120.

2. Brown PD, Lerner SA. Community-acquired pneumonia. Lancet 1998;352:1295-302.

3. File TM. Community-acquired pneumonia. Lancet 2003;362:19912001.

4. Menendez R, Torres A, Zalacain R, Aspa J, Martin Villasclaras JJ, Borderias $\mathrm{L}$, et al. Risk factors of treatment failure in community acquired pneumonia: implications for disease outcome. Thorax 2004:59:960-5.

5. Almirall J, Bolibar I, Vidal J, Sauca G, Coll P, Niklasson B, et al. Epidemiology of community-acquired pneumonia in adults: a population-based study. Eur Respir J 2000;15:757-63. 
6. Alan M, Grolimund E, Kutz A, Christ-Crain M, Thomann R, Falconnier $\mathrm{C}$, et al. Clinical risk scores and blood biomarkers as predictors of long-term outcome in patients with community-acquired pneumonia: a 6-year prospective follow-up study. J Intern Med 2015;278:174-84.

7. Restrepo MI, Faverio P, Anzueto A. Long-term prognosis in community-acquired pneumonia. Curr Opin Infect Dis 2013;26:151-8.

8. Kellum JA, Kong L, Fink MP, Weissfeld LA, Yealy DM, Pinsky $M R$, et al. Understanding the inflammatory cytokine response in pneumonia and sepsis: results of the Genetic and Inflammatory Markers of Sepsis (GenIMS) Study. Arch Intern Med 2007;167:1655-63.

9. Guertler C, Wirz B, Christ-Crain M, Zimmerli W, Mueller B, Schuetz P. Inflammatory responses predict long-term mortality risk in community-acquired pneumonia. Eur Respir J 2011;37:1439-46.

10. Schuetz P, Suter-Widmer I, Chaudri A, Christ-Crain M, Zimmerli W, Mueller B, et al. Prognostic value of procalcitonin in community-acquired pneumonia. Eur Respir J 2011;37:384-92.

11. Suter-Widmer I, Christ-Crain M, Zimmerli W, Albrich W, Mueller $B$, Schuetz P, et al. Predictors for length of hospital stay in patients with community-acquired pneumonia: results from a Swiss multicenter study. BMC Pulm Med 2012;12:21.

12. Corrales-Medina VF, Alvarez KN, Weissfeld LA, Angus DC, Chirinos JA, Chang CC, et al. Association between hospitalization for pneumonia and subsequent risk of cardiovascular disease. J Am Med Assoc 2015;313:264-74.

13. Fine MJ, Auble TE, Yealy DM, Hanusa BH, Weissfeld LA, Singer DE, et al. A prediction rule to identify low-risk patients with community-acquired pneumonia. N Engl J Med 1997;336:243-50.

14. Zhydkov A, Christ-Crain M, Thomann R, Hoess C, Henzen C, Werner Z, et al. Utility of procalcitonin, C-reactive protein and white blood cells alone and in combination for the prediction of clinical outcomes in community-acquired pneumonia. Clin Chem Lab Med 2015;53:559-66.

15. Schuetz P, Hausfater P, Amin D, Amin A, Haubitz S, Faessler L, et al. Biomarkers from distinct biological pathways improve early risk stratification in medical emergency patients: the multinational, prospective, observational TRIAGE study. Crit Care 2015;19:377.

16. Kutz A, Briel M, Christ-Crain M, Stolz D, Bouadma L, Wolff M, et al. Prognostic value of procalcitonin in respiratory tract infections across clinical settings. Crit Care 2015;19:74.

17. Grolimund E, Kutz A, Marlowe RJ, Vogeli A, Alan M, Christ-Crain $M$, et al. Long-term prognosis in COPD exacerbation: role of biomarkers, clinical variables and exacerbation type. COPD 2015;12:295-305.

18. Debiane L, Hachem RY, Al Wohoush I, Shomali W, Bahu RR, Jiang $\mathrm{Y}$, et al. The utility of proadrenomedullin and procalcitonin in comparison to $\mathrm{C}$-reactive protein as predictors of sepsis and bloodstream infections in critically ill patients with cancer*. Crit Care Med 2014;42:2500-7.

19. Schuetz P, Maurer P, Punjabi V, Desai A, Amin DN, Gluck E. Procalcitonin decrease over 72 hours in US critical care units predicts fatal outcome in sepsis patients. Crit Care 2013;17:R115.

20. Schuetz P, Litke A, Albrich WC, Mueller B. Blood biomarkers for personalized treatment and patient management decisions in community-acquired pneumonia. Curr Opin Infect Dis 2013;26:159-67.
21. Suberviola B, Castellanos-Ortega A, Llorca J, Ortiz F, Iglesias D, Prieto $B$. Prognostic value of proadrenomedullin in severe sepsis and septic shock patients with community-acquired pneumonia. Swiss Med Wkly 2012;142:w13542.

22. Christ-Crain M, Morgenthaler NG, Stolz D, Muller C, Bingisser $\mathrm{R}$, Harbarth S, et al. Pro-adrenomedullin to predict severity and outcome in community-acquired pneumonia [ISRCTN04176397]. Crit Care 2006;10:R96.

23. Huang DT, Angus DC, Kellum JA, Pugh NA, Weissfeld LA, Struck J, et al. Midregional proadrenomedullin as a prognostic tool in community-acquired pneumonia. Chest 2009;136:823-31.

24. Kruger S, Ewig S, Giersdorf S, Hartmann O, Suttorp N, Welte T, et al. Cardiovascular and inflammatory biomarkers to predict short- and long-term survival in community-acquired pneumonia: Results from the German Competence Network, CAPNETZ. Am J Respir Crit Care Med 2010;182:1426-34.

25. Schuetz P, Wolbers M, Christ-Crain M, Thomann R, Falconnier C, Widmer I, et al. Prohormones for prediction of adverse medical outcome in community-acquired pneumonia and lower respiratory tract infections. Crit Care 2010;14:R106.

26. Albrich WC, Dusemund F, Ruegger K, Christ-Crain M, Zimmerli W, Bregenzer T, et al. Enhancement of CURB65 score with proadrenomedullin (CURB65-A) for outcome prediction in lower respiratory tract infections: derivation of a clinical algorithm. BMC Infect Dis 2011;11:112.

27. Bello S, Lasierra AB, Minchole E, Fandos S, Ruiz MA, Vera E, et al. Prognostic power of proadrenomedullin in communityacquired pneumonia is independent of aetiology. Eur Respir J 2012;39:1144-55.

28. Renaud B, Schuetz P, Claessens YE, Labarere J, Albrich W, Mueller B. Proadrenomedullin improves Risk of Early Admission to ICU score for predicting early severe community-acquired pneumonia. Chest 2012;142:1447-54.

29. Courtais C, Kuster N, Dupuy AM, Folschveiller M, Jreige R, Bargnoux AS, et al. Proadrenomedullin, a useful tool for risk stratification in high Pneumonia Severity Index score community acquired pneumonia. Am J Emerg Med 2013;31:215-21.

30. Gordo-Remartinez S, Calderon-Moreno M, Fernandez-Herranz J, Castuera-Gil A, Gallego-Alonso-Colmenares M, Puertas-Lopez C, et al. Usefulness of midregional proadrenomedullin to predict poor outcome in patients with community acquired pneumonia. PLoS One 2015;10:e0125212.

31. Kruger S, Ewig S, Kunde J, Hartmann O, Suttorp N, Welte T, et al. Pro-atrial natriuretic peptide and pro-vasopressin for predicting short-term and long-term survival in community-acquired pneumonia: results from the German Competence Network CAPNETZ. Thorax 2010;65:208-14.

32. Kruger S, Papassotiriou J, Marre R, Richter K, Schumann C, von Baum H, et al. Pro-atrial natriuretic peptide and pro-vasopressin to predict severity and prognosis in community-acquired pneumonia: results from the German competence network CAPNETZ. Intensive Care Med 2007;33:2069-78.

33. Muller B, Suess E, Schuetz P, Muller C, Bingisser R, Bergmann A, et al. Circulating levels of pro-atrial natriuretic peptide in lower respiratory tract infections. J Intern Med 2006;260:568-76.

34. Haeuptle J, Zaborsky R, Fiumefreddo R, Trampuz A, Steffen I, Frei $R$, et al. Prognostic value of procalcitonin in Legionella pneumonia. Eur J Clin Microbiol Infect Dis 2009;28:55-60.

35. Kruger S, Ewig S, Marre R, Papassotiriou J, Richter K, von Baum $\mathrm{H}$, et al. Procalcitonin predicts patients at low risk of death from 
community-acquired pneumonia across all CRB-65 classes. Eur Respir J 2008;31:349-55.

36. Muller B, Harbarth S, Stolz D, Bingisser R, Mueller C, Leuppi J, et al. Diagnostic and prognostic accuracy of clinical and laboratory parameters in community-acquired pneumonia. BMC Infect Dis 2007;7:10.

37. Schuetz P, Christ-Crain M, Thomann R, Falconnier C, Wolbers $\mathrm{M}$, Widmer I, et al. Effect of procalcitonin-based guidelines vs. standard guidelines on antibiotic use in lower respiratory tract infections: the ProHOSP randomized controlled trial. J Am Med Assoc 2009;302:1059-66.

38. Schuetz P, Christ-Crain M, Wolbers M, Schild U, Thomann R, Falconnier $\mathrm{C}$, et al. Procalcitonin guided antibiotic therapy and hospitalization in patients with lower respiratory tract infections: a prospective, multicenter, randomized controlled trial. BMC Health Serv Res 2007;7:102.

39. Gonzales R, Sande MA. Uncomplicated acute bronchitis. Ann Intern Med 2000;133:981-91.

40. Niederman MS, Mandell LA, Anzueto A, Bass JB, Broughton WA Campbell GD, et al. Guidelines for the management of adults with community-acquired pneumonia. Diagnosis, assessment of severity, antimicrobial therapy, and prevention. Am J Respir Crit Care Med 2001;163:1730-54

41. Woodhead M, Blasi F, Ewig S, Huchon G, leven M, Ortqvist A, et al. Guidelines for the management of adult lower respiratory tract infections. Eur Respir J 2005;26:1138-80.

42. Mandell LA, Wunderink RG, Anzueto A, Bartlett JG, Campbell GD, Dean NC, et al. Infectious Diseases Society of America/American Thoracic Society consensus guidelines on the management of community-acquired pneumonia in adults. Clin Infect Dis 2007;44(Suppl 2):S27-72.

43. Struck J, Tao C, Morgenthaler NG, Bergmann A. Identification of an Adrenomedullin precursor fragment in plasma of sepsis patients. Peptides 2004;25:1369-72.

44. Morgenthaler NG, Struck J, Alonso C, Bergmann A. Measurement of midregional proadrenomedullin in plasma with an immunoluminometric assay. Clin Chem 2005;51:1823-9.

45. Morgenthaler NG, Struck J, Thomas B, Bergmann A. Immunoluminometric assay for the midregion of pro-atrial natriuretic peptide in human plasma. Clin Chem 2004;50:234-6.

46. Schrag A, Selai C, Jahanshahi M, Quinn NP. The EQ-5D-a generic quality of life measure-is a useful instrument to measure quality of life in patients with Parkinson's disease. J Neurol Neurosurg Psychiatry 2000;69:67-73.

47. EuroQol G. EuroQol-a new facility for the measurement of health-related quality of life. Health Policy 1990;16:199-208.

48. Brooks R. EuroQol: the current state of play. Health Policy 1996;37:53-72.

49. Shaw JW, Johnson JA, Coons SJ. US valuation of the EQ-5D health states: development and testing of the D1 valuation model. Med Care 2005;43:203-20.
50. Kitamura K, Kangawa K, Kojima M, Ichiki Y, Matsuo H, Eto T. Complete amino acid sequence of porcine adrenomedullin and cloning of cDNA encoding its precursor. FEBS Lett 1994;338:306-10.

51. Temmesfeld-Wollbruck B, Hocke AC, Suttorp N, Hippenstiel S. Adrenomedullin and endothelial barrier function. Thromb Haemost 2007;98:944-51.

52. Hao SL, Yu ZH, Qi BS, Luo JZ, Wang WP. The antifibrosis effect of adrenomedullin in human lung fibroblasts. Exp Lung Res 2011;37:615-26.

53. Marinoni E, Pacioni K, Sambuchini A, Moscarini M, Letizia C, DI Iorio R. Regulation by hypoxia of adrenomedullin output and expression in human trophoblast cells. Eur J Obstet Gynecol Reprod Biol 2011;154:146-50.

54. Martinez A, Miller MJ, Unsworth EJ, Siegfried JM, Cuttitta F. Expression of adrenomedullin in normal human lung and in pulmonary tumors. Endocrinology 1995;136:4099-105.

55. Eto T. A review of the biological properties and clinical implications of adrenomedullin and proadrenomedullin $\mathrm{N}$-terminal 20 peptide (PAMP), hypotensive and vasodilating peptides. Peptides 2001;22:1693-711.

56. Linscheid P, Seboek D, Zulewski H, Keller U, Muller B. Autocrine/ paracrine role of inflammation-mediated calcitonin gene-related peptide and adrenomedullin expression in human adipose tissue. Endocrinology 2005;146:2699-708.

57. Stolz D, Kostikas K, Blasi F, Boersma W, Milenkovic B, Lacoma A, et al. Adrenomedullin refines mortality prediction by the BODE index in COPD: the "BODE-A" index. Eur Respir J 2014;43:397408.

58. Pfeil U, Aslam M, Paddenberg R, Quanz K, Chang CL, Park $\mathrm{Jl}$, et al. Intermedin/adrenomedullin-2 is a hypoxia-induced endothelial peptide that stabilizes pulmonary microvascular permeability. Am J Physiol Lung Cell Mol Physiol 2009;297:L837-45.

59. Di Paola R, Talero E, Galuppo M, Mazzon E, Bramanti P, Motilva $\mathrm{V}$, et al. Adrenomedullin in inflammatory process associated with experimental pulmonary fibrosis. Respir Res 2011;12:41.

60. Qi JG, Ding YG, Tang CS, Du JB. Chronic administration of adrenomedullin attenuates hypoxic pulmonary vascular structural remodeling and inhibits proadrenomedullin N-terminal 20-peptide production in rats. Peptides 2007;28:910-9.

61. Haviv M, Haver E, Lichtstein D, Hurvitz H, Klar A. Atrial natriuretic peptide in children with pneumonia. Pediatr Pulmonol 2005;40:306-9.

62. Vesely DL. Atrial natriuretic peptide prohormone gene expression: hormones and diseases that upregulate its expression. IUBMB Life 2002;53:153-9.

63. Aiura K, Ueda M, Endo M, Kitajima M. Circulating concentrations and physiologic role of atrial natriuretic peptide during endotoxic shock in the rat. Crit Care Med 1995;23:1898-906. 